\title{
Gold source and occurrence in pyrite and telluride mineralogy of the Laowan Au-Ag-Te deposit, Qinling-Dabie orogenic belt, central China: a new evidence for a magmatic source of hydrothermal fluids, and implications for ore genesis and physicochemical conditions
}

\author{
Weikan Jin ${ }^{1}$, Shouyu Chen ${ }^{2}$ \\ 1 [ ${ }^{1}$ Faculty of Earth Resources,China University of Geosciences, Wuhan 430074, China.407349895@qq.com] \\ $2\left[{ }^{2}\right.$ State Key Laboratory of Geological Processes and Mineral Resources, China University of Geosciences, Wuhan \\ 430074, China.45321870@qq.com]
}

The Mesozoic Laowan gold deposit in Tongbai district, Henan province, China, is situated centrally in the Qinling-Dabie orogenic belt. This deposit is a defined reserve of approximately $>100 \mathrm{t}$ and represents a recent breakthrough in gold prospecting in the Qinling-Dabie orogenic belt. Ongoing disagreements about the mechanisms of mineralization, source of materials, and the form in which gold occurs directly affect potential resource recovery in deep and peripheral areas. A tunnel geological survey and mineral identification via a microscope, combined with EMPA/EDS mapping and LA-ICP-MS analysis, established the types of minerals present. The sequence of their formation and symbiosis was determined by studying the Au-hosting mineral geochemical element typomorphism to provide the basis for the occurrence of $\mathrm{Au}$, sources of ore-forming fluid and material, and the genesis and mineralization mechanism of pyrite. The results show that: (1) the 5generation pyrite in 4 stages during mineralization was identified: coarse-grained pyrite(Py1)-quartz and medium- to fine-grained euhedral to subhedral fracture structure grains pyrite(Py2)-quartz in Stage I; medium- to fine-grained compacting pyrite(Py3)-quartz in Stage II; pyrite(Py4)polymetallic sulfide stage (Stage III) and carbonate-quartz-pyrite(Py5) stage (Stage IV). The Py1 and Py2 contains negligible to low levels of gold, whereas both invisible and visible gold mainly occurrs in Py3 and Py4. (2) LA-ICP-MS analysis shows that Py3 and Py4 are concentrated Au-Ag$\mathrm{Bi}-\mathrm{Te}$, with a prominent correlation between $\mathrm{Au}$ and $\mathrm{Ag}$, as well as $\mathrm{Te}$ and $\mathrm{Bi}$. In the mineralization stages, Au present as visible native gold and electrum, and some of them also occur as an invisible solid inclusions of tellurides or nanoparticles in the pyrite crystal lattice. All pyrites are rich in As and auriferous pyrites are rich in both As and Te, the enrichment of $\mathrm{Au}$ is unrelated to As. Te has been an important scavenger of gold in the condition of high tellurium fugacity. (3) The observed $\mathrm{Co} / \mathrm{Ni}$ values and Se concentrations indicate that Py1and Py2 in the early mineralization mainly reflects metamorphic sedimentary genesis, and implying that took place reaction with the wall rock or hydrothermal remobilization. The pyrites(Py3 and Py4) in the main mineralization stages mostly reflect hydrothermal genesis and imply that magmatic water was added during their formation. (4) Tellurides are widespread in the main metallogenic auriferous pyrites, consisting of petzite, calaverite, tellurobismuthite, tetradymite, volynskite and hessite, provide new evidence for a magmatic source of hydrothermal fluids. Tellurides are commonly associated with native gold. Lopsided mineral imply the precipitation of tellurides under fluctuant chemical conditions. The $\mathrm{Bi} /(\mathrm{Te}+\mathrm{S})$ of $\mathrm{Te}-\mathrm{Bi}$ minerals and the the vertical zonal characteristics of different telluride 
combinations indicate that the precipitation of gold is under variable redox conditions. (5) The paragenetic association of tellurides, when combined with fluid inclusion microthermometric data and information about the stability of sulfide and telluride minerals, permits an estimate for the conditions responsible for telluride formation. From $250^{\circ} \mathrm{C}$ to $200^{\circ} \mathrm{C}, \operatorname{logfTe} 2$ and $\operatorname{logfS} \mathrm{S}_{2}$ decreased from -13.0 -8.3 and -14.7 -8.6 to -15.2 -11.2 and -16.7 -10.5, respectively. Sulfur and tellurium fugacity and temperature are the major factors governing the formation and evolution of telluride assemblages. (6) Enrichment of Au-Ag-Te-Bi and the transformation of metallogenic conditions indicates that ore-forming fluids and metals might be stem from a mantle-derived magmatic system. The metallogenic process possibly be the metamorphic sedimentary pyrite is lack of gold in the early mineralization, the addition of mantle-derived magmatic brought metallogenic materials and metallogenic fluids during the main stage of metallogenesis, the ore-forming environment is under reduced conditions in the deep, initially. Au-Ag-Bi-Te minerals are formed under high tellurium fugacity conditions; accompanied by decrease of temperature and precipitation of a large quantity of tellurides, and the gradual decrease in mineralization depth and subsequent addition of atmospheric water, leading to tremendous decrease of tellurium fugacity, the ore-forming environment evolves from reductive condition to the oxidizing conditions. The results indicate that the Laowan gold deposit may have resulted from multi-stage mineralization.

Keywords: Laowan gold deposit, Qinling-Dabie orogenic belt, pyrite, tellurides, gold occurrence, trace element 